\title{
2,13-Diaza[5]helicene: synthesis, theoretical calculations and spectroscopic properties
}

\author{
Tullio Caronna, ${ }^{a *}$ Francesca Fontana, ${ }^{a}$ Giovanna Longhi, ${ }^{b}$ Andrea Mele,, d Isabella Natali \\ Sora, ${ }^{a}$ and Luca Viganò ${ }^{a}$ \\ ${ }^{a}$ Dipartimento di Ingegneria Industriale, Università di Bergamo, Viale Marconi 5, 24044 \\ Dalmine, BG, Italy \\ ${ }^{b}$ Dipartimento di Scienze Biomediche e Biotecnologie, Università di Brescia, viale Europa 11, \\ 25123 Brescia, Italy \\ ${ }^{c}$ Dipartimento di Chimica, Materiali e Ingegneria Chimica G..Natta, Politecnico di Milano, via \\ L. Mancinelli 7, 20131 Milano, Italy \\ ${ }^{d}$ CNR - Istituto di Chimica del Riconoscimento Molecolare, via L. Mancinelli 7, 20131 Milano, \\ Italy
}

E-mail: tullio.caronna@unibg.it

This paper is dedicated to Professor Nicolò Vivona for his $70^{\text {th }}$ birthday

\begin{abstract}
An easy approach to the synthesis of azahelicenes is based on the photochemical cyclisation of symmetrically or asymmetrically 1,2-aryl-substituted double bonds. In the synthesis of 2,13diaza[5]helicene, irradiation of 9-(2-pyridin-4-yl-vinyl)-benzo[h]isoquinoline yielded 2,9-diazadibenzo[a.h]anthracene together with the desired helicene, and the ratio of the two products depends on the solvent. In this paper we suggest that the ratio between the two products should not be ascribed to different transitions induced by the solvent but to different populations of the two $\mathrm{Z}$ conformers
\end{abstract}

Keywords: 2,13-Diaza[5]helicene, 2,9-diaza-dibenzo[a.h]anthracene, solvent polarity, photochemical ring closure, theoretical calculations, NMR

\section{Introduction}

In the series of aza[5]helicenes, the ones containing one or two nitrogen atoms are particularly attractive in view of forming complexes with metal ions. ${ }^{1}$ In the past, we reported the synthesis 
of a certain number of monoaza ${ }^{2,3}$ and diazahelicenes ${ }^{3}$, generally utilizing a photochemical approach.

However, for the synthesis of 2-aza[5]helicene a non photochemical approach was employed. ${ }^{2}$ The reason was that the photochemical ring closure of all possible precursors to this molecule, namely 7-(2-naphthalen-2-yl-vinyl)-isoquinoline (1), 4-(2-phenanthren-3-yl-vinyl)pyridine (2) and 9-styryl-benzo[h]isoquinoline (3) all brought exclusively to the corresponding perylene (4) (Scheme 1) .
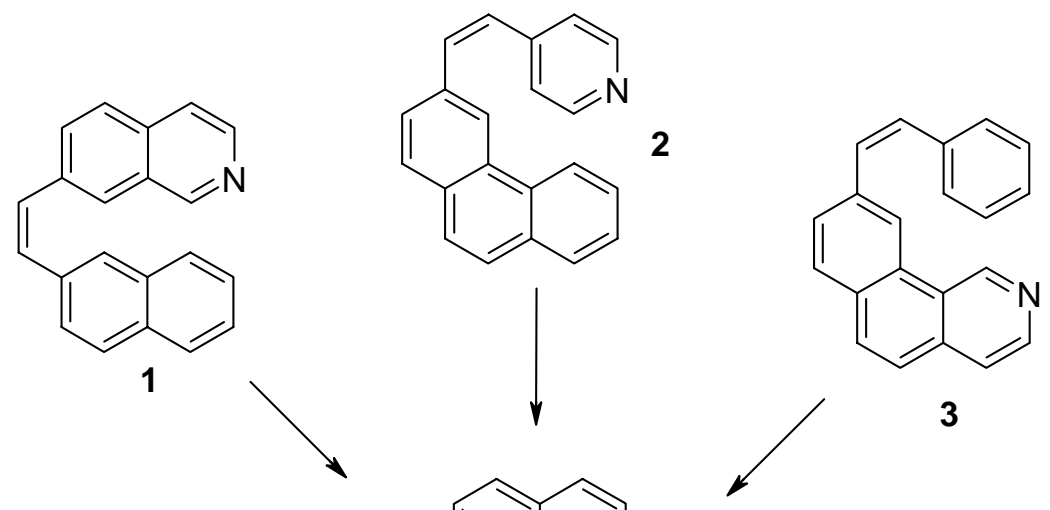

\section{Scheme 1}

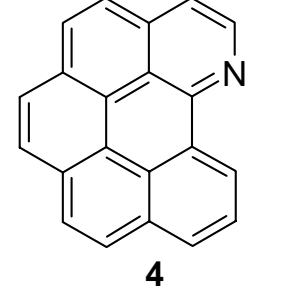

Theoretical calculations suggested that the perylene formation is, by far, the favored photochemical closure. ${ }^{2}$ Similar difficulties were anticipated in designing the photochemical synthesis of 2,13-diaza[5]helicene, and for this reason a non-photochemical approach was devised at first, but the overall yield was extremely low, ${ }^{4}$ so as to call for a different approach.

\section{Results and Discussion}

Interestingly, ab initio calculations performed on $\mathbf{6}$ showed similarities with other calculations referred to those monoazahelicenes which can be obtained by irradiation so as to predict the possibility to obtain 5 photochemically. Furthermore, these calculations suggested also that irradiation would yield not only the helicene, but also 2,9-diaza-dibenzo[a.h]anthracene (7) from a competing pathway (Scheme 2). 
<smiles>[Z20]#Cc1ccc2ccc(/C=C\c3ccncc3)cc2c1</smiles><smiles></smiles>

5
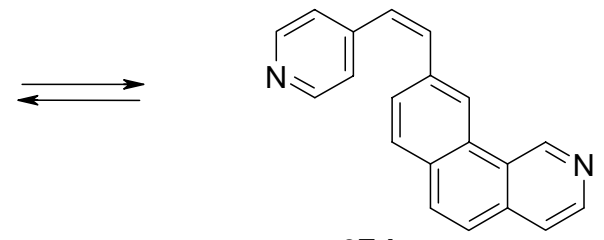

6Z-b

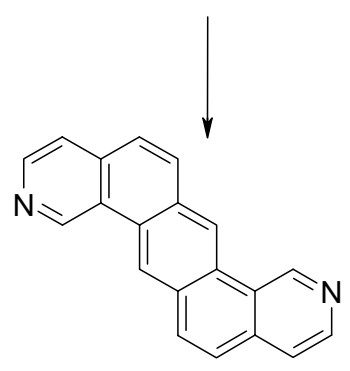

7

\section{Scheme 2}

As described in ref. 2 we considered a "free valence" atomic index, analogous to the one introduced in the context of the Hückel model. ${ }^{5 a, b}$ We examined the two possible conformations 6Z-a and 6Z-b: the first one with the pyridine ring oriented inwards, in a geometry close to (5), the second one with the pyridine ring oriented outwards, similar to (7) (Scheme 2).

The presence of these two conformations in solution was confirmed by NMR. Compound $6 \mathrm{Z}$ was examined in both benzene- $\mathrm{d}_{6}$ and methanol- $\mathrm{d}_{4}$. Steady state nuclear Overhauser enhancement (NOE) experiments were carried out in order to assess the conformational preferences. NOE difference spectra pointed out that, in both cases, conformers 6Z-a and 6Z-b are present in solution and in fast exchange on the NMR time-scale. The results are summarized in Table 1.

Table 1. NOE data of compound 6Z. In parentheses the conformer consistent with observed NOE (legend: $\mathrm{a}=\mathbf{6 Z - a} ; \mathrm{b}=\mathbf{6 Z - b}$, see Scheme 2)

\begin{tabular}{ccc}
\hline Irradiated & Observed NOE \% (conf.) & Observed NOE \% (conf.) \\
& benzene-d6 & methanol-d4 \\
\hline H10 & H2,2'(py) 2.8\% (a) & H2,2'(py) 1.2\% (a) \\
& H11(vinylic) 3.5\% (b) & H11(vinylic) 5.1\% (b) \\
H2,2'(py) & H10 1.0\% (a) & H10 1.2\% (a) \\
& H8 1.0\% (b) & H8 1.3\% (b) \\
H11(vinylic) & H10 2.2\% (a) & H10 2.9\% (a) \\
& H8 0.4\% (b) & H8 1.9\% (b) \\
\hline
\end{tabular}

Unfortunately, the expected stabilization of a single conformation by varying the solvent polarity was not observed. As a matter of fact, in both solvents, the two conformations depicted 
in Scheme 1 are appreciably populated. Cautious use of quantitative NOE \% data seems to suggest that $\mathbf{6 Z - a}$ is slightly stabilized with respect to $6 \mathbf{Z}-\mathbf{b}$ in methanol- $\mathrm{d}_{4}$, and the vice versa in benzene- $\mathrm{d}_{6}$.

The two conformers may be considered precursors of 5 and 7 respectively (Scheme 2). Excited states of these two conformers have been optimized in the CIS framework with 6-31G basis set; this permits a comparison with data obtained previously; ${ }^{5}$ we used the GAUSSIAN03 package. ${ }^{6}$ In all cases the conformers are distorted, the pyridine ring and the phenanthridine system lying in two different planes: the dihedral angles responsible for non-planarity are torsions about the simple CC bonds at the ground state (optimization B3LYP/6-31G), and the torsion about the double bond at the first excited state (CIS).

In our previous paper, ${ }^{2}$ in order to find an explanation to the different outputs of the experiments for the production of helicenes, the value of an atomic index had been calculated by means of the Natural Bond Orbital program ${ }^{7}$ included in the package GAUSSIAN03. We defined an atomic quantity $F_{A}$ that mimics the "free valence" atomic index introduced in the past in the context of the Hückel model. ${ }^{4 a, b}$

$$
F_{A}=V_{A}-\sum_{B \neq A} b^{(w)} A B
$$

where $V_{A}$ is the atomic valence returned by the NBO program as the sum of occupation numbers of the valence orbitals (as opposed to core orbitals) of atom $A, b^{(w)}{ }_{A B}$ is the Wiberg bond index $^{7 \mathrm{a}, \mathrm{b}}$ of atoms $A$ and $B$, and the sum is made over all the atoms $B$ other than $A$. The above index has been calculated in the first excited state for the atoms of interest $\left(F_{A}{ }^{*}\right)$.

In Table 2 we report the values of the differences $\Delta \mathrm{F}^{*}=\left|\mathrm{F}^{*} \mathrm{X}^{-\mathrm{F}^{*}} \mathrm{Y}\right|, \mathrm{X}$ and $\mathrm{Y}$ being the carbon atoms possibly involved in the closure.

Table 2. Difference of the bond indexes for the atoms involved in the ring formation

$\Delta F^{*}=\left|F_{X}^{*}-F_{Y}^{*}\right|$

It has been reported for monoaza-compounds (see for example ref. 5b and references cited therein) that the closure yielding the helicene is favoured with respect to the formation of the anthracene, and that this fact corresponds to the highest values for $\Delta \mathrm{F}^{*}$. In the case of the precursor of 2-aza[5]helicene instead, the highest value for $\Delta \mathrm{F}^{*}$ regards the two carbons 
corresponding to the closure giving (4) and in fact no trace of the 2-aza[5]helicene was detected in the photochemical reaction. In the case of monoaza-compounds it was found that all the conformers similar to $\mathbf{6 Z}-\mathbf{b}$ have lower values for $\Delta \mathrm{F}^{*}$, minor than half the value obtained for the conformers of type 6Z-a; actually, for monoaza compounds no dibenzoanthracene byproducts were detected, despite the fact that the energies for $\mathbf{b}$ conformers are slightly lower than the energies for $\mathbf{a}$.

In the case of 2,13-diaza[5]helicene here considered, the same kind of calculations gave a lower value of $\Delta \mathrm{F}^{*}$ in case of conformer $\mathbf{6 Z}$-b than for conformer 6Z-a; however the difference is small: this suggests that (5) may be obtained together with (7) through two competing pathways.

The theoretical work needed to understand the photochemical process is beyond the scope of this work; what reported is just a preliminary indication to guide the choice of the chemical route but only a real experiment can say the last word. Remarkably, however, the example reported here is another instance of good correlation between calculation and experiment in the same framework. For these reasons, photochemical synthesis of 5 was attempted, starting from (6); this latter could be obtained through several alternative synthetic routes.

(a) the direct condensation of $\mathbf{8}$ with 4-methyl pyridine to give the precursor $\mathbf{6 - E}$, (Scheme 3)

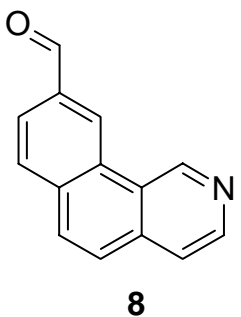

8

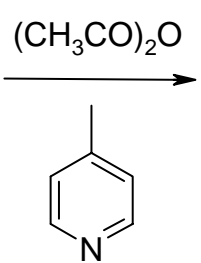

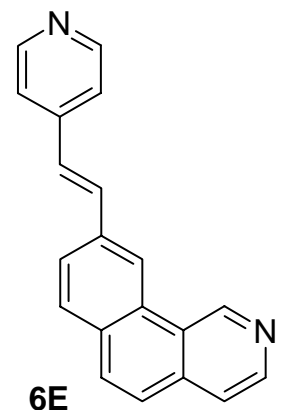

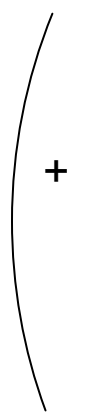

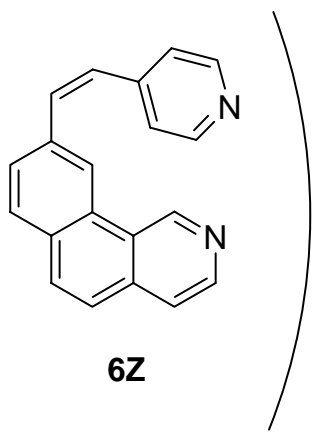

\section{Scheme 3}

(b) The reaction of $\mathbf{8}$ with pyridin-4-yl-methyl-triphenylphosphonium bromide . In this case a mixture of the $\mathrm{Z}(80 \%)$ and $\mathrm{E}(20 \%)$ isomers of $\mathbf{6}$ is obtained

(c) The Mizoroki-Heck coupling; considering that 4-vinyl pyridine is a common product, and the counterpart, 9-Br-Benzo[h]isoquinoline is easy to synthesise, ${ }^{9}$ this could be considered a viable alternative approach, but our attempts to obtain (6) following this procedure ${ }^{10 a-d}$ gave very low yields.

Once $\mathbf{6}$ is obtained, a first photolysis experiment was run in ethyl acetate and, as expected, both products 5 and 7 were obtained in a 6.8 to 1 ratio. However, in order to raise the yield of 2 , the reaction was conducted in different solvents to explore the possibility of exploiting polarity effects. The results are shown in Figure 1. 


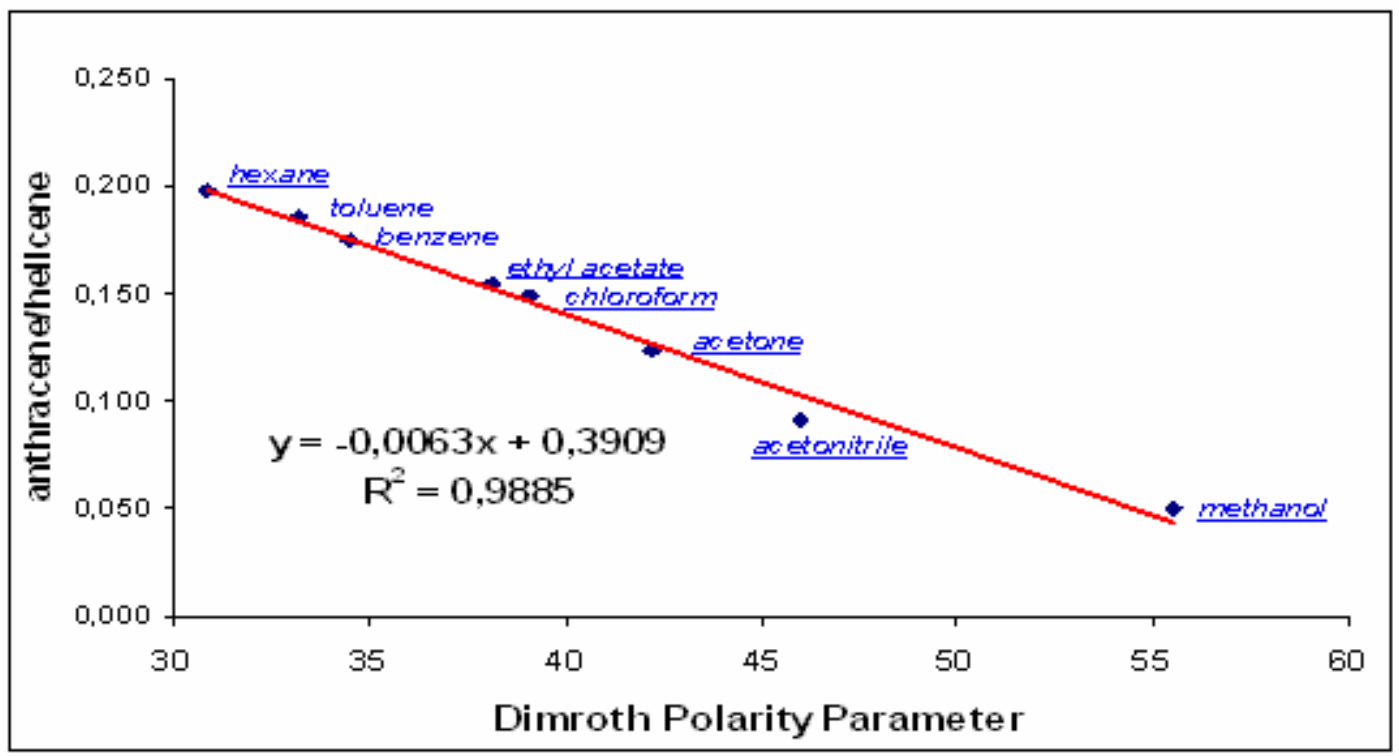

Figure 1. Correlation between the Dimroth solvent polarity parameter and the ratio anthracene/phenanthrene.

A simple explanation of the trend evidenced in Figure1 may be that in non polar solvents 6 interacts preferentially with the solvent molecules, stabilizing to a certain extent the open conformation 6Z-b that would bring to 7, while in polar solvents an intramolecular interaction stabilizing 6Z-a must be preferred, eventually giving 5 as main product.

Since the mechanism of formation is likely the same for both products, the absence of changes due to solvent polarity in the energy of the transitions ${ }^{10}$ were excluded by analysis of the absorption and the emission spectra of the $\mathrm{Z}$ isomer in some of the used solvents.

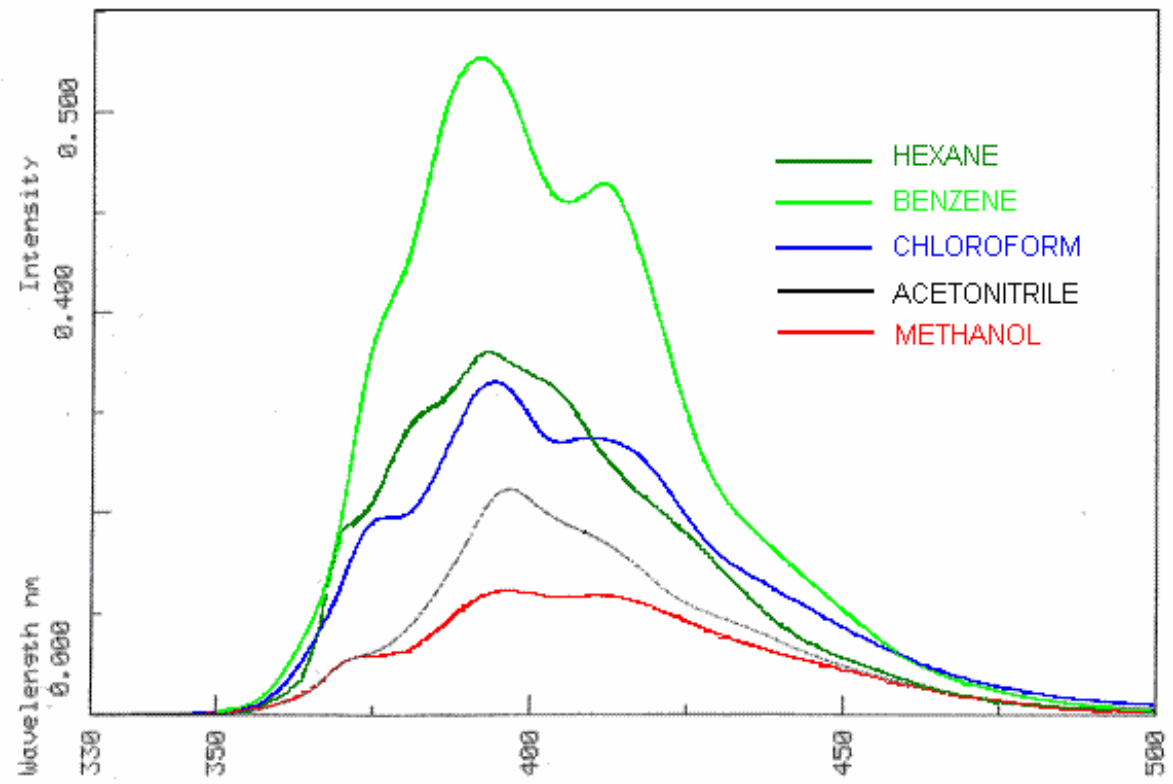

Figure 2. Emission spectra of 6-Z in selected solvents. 
The shift of maxima in the different solvents is very limited both for absorption and emission spectra, though some differences are observed in the intensity of emitted light (Figure 2). Indeed, calculations allow to predict a huge difference in the dipole moment of the 6Z-a and 6Z-b conformers both in the ground state and in the excited state, as can be seen in Table 3

Table 3. Calculated dipole moments in Debye for the ground and excited states of 6Z-a and 6Zb conformers

\begin{tabular}{ccc}
\hline & $\mathbf{6 Z - a}$ & $\mathbf{6 Z - b}$ \\
\hline Ground state & 5.14 & 2.06 \\
Excited state & 5.67 & 2.66 \\
\hline
\end{tabular}

It can be also remarked that ring closure to give $\mathbf{5}$ is by far the preferred pathway compared to the one giving $\mathbf{7}$. This means that the excited state of $\mathbf{6 Z - b}$ may live long enough to choose between two deactivation channels: light emission or ring closure. Oppositely, ring closure is strongly favoured for $\mathbf{6 Z - a}$ and the channel of deactivation through emission is inactive in this case. Consequently, the fluorescence emissions are indicative of the population of the two conformers 6Z-a and 6Z-b. The only exception to this trend is observed in benzene, where the relative emission is much higher than in the other cases and for which we see no simple explanation.

Finally, prolonged irradiation brings to the formation of 7,8-diaza-benzo[ghi]perylene (9), but differently from the cases of (2) and (3) in Scheme 1, here the products derives from reaction of the photochemically excited helicene (Scheme 4). In the Scheme, the numbering used in the discussion of the NMR spectra is included.

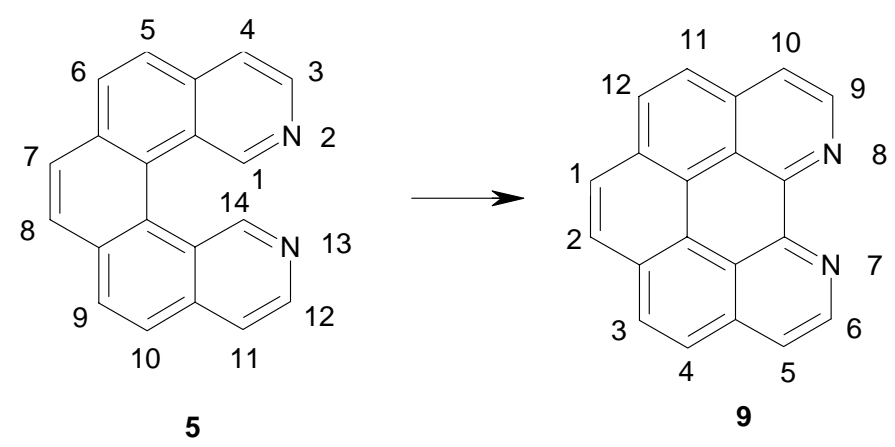

\section{Scheme 4}

\section{Conclusions}

Differently from the photochemical synthesis of the other mono- and diaza[5]helicenes, irradiation of 9-(2-pyridin-4-yl-vinyl)-benzo[ $h]$ isoquinoline gives rise to the formation not only of helicene 5, but also of the competing product 7; their ratio depends on the polarity of the used 
solvent. A theoretical explanation of the observed trends is proposed. The perylene $\mathbf{9}$ is formed only for prolonged irradiation, at variance with the behaviour described for the related compound 4.

\section{Experimental Section}

Ab initio calculations. GAUSSIAN03 package was used. ${ }^{6}$ Ground state has been optimized at B3LYP/6-31G level; optimization on excited states has been done using single-excitation configuration interaction, CIS, with the same basis set. Natural Bond Orbital program ${ }^{7}$ included $^{2}$ in the package GAUSSIAN03 has been used to calculate atom indices.

General Procedures. All solvents were distilled and dried before use. 4-picoline, 4vinylpyridine, triphenylphosphine, acetic anhydride, are commercial products and were used without further purification. Irradiations were carried out on a Rayonet RPR-100 photochemical reactor equipped with 16 interchangeable lamps irradiating either at 254, 313, or $365 \mathrm{~nm}$ as well as in the visible range, dissolving the substance in the appropriate solvent in quartz or Pyrex vessels, depending on the used wavelength.

\section{9-[2-Pyridin-4-yl-vinyl]-benzo[h]isoquinoline (6)}

Method A. 4-methylpyridine $(0.16 \mathrm{~mL}, 1.6 \mathrm{mmol})$ was refluxed with aldehyde 8 (0.070 g, $0.33 \mathrm{mmol}$ ) in acetic anhydride $(15 \mathrm{~mL})$ for $48 \mathrm{~h}$. After cooling at room temperature, a $2 \mathrm{M}$ aqueous solution of $\mathrm{NaOH}$ was carefully added on cooling with an external ice bath, and the solution extracted not less than 4 times with $10 \mathrm{~mL}$ portions of $\mathrm{CH}_{2} \mathrm{Cl}_{2}$. After drying and solvent evaporation, the residue $(0.186 \mathrm{~g})$ was chromatographed on silica gel (Ethyl acetate and then Ethyl acetate: ethanol 4:1) recovering 8 (0.028 g) and obtaining 6-E as a yellow solid in 27\% yield (0.040 g).

Method B. In a flask containing a mixture of the aldehyde 8 (1 mmol) and MeONa (0.065 g, $1.2 \mathrm{mmol})$, pyridin-4-ylmethyl-triphenylphosphonium bromide (1 mmol) in methanol (15 $\mathrm{mL})$, was dropped during $3 \mathrm{~h}$ under stirring and boiling. After cooling, water was added, and the solution extracted not less than 4 times with a large volume of $\mathrm{CH}_{2} \mathrm{Cl}_{2}$. After drying and solvent evaporation, the residue was chromatographed on silica gel (Ethyl acetate and then Ethyl acetate/ethanol 4:1) obtaining 6 as a deliquescent brownish yellow solid in (0.240 g, 85\% yield) (20\% E isomer $80 \% \mathrm{Z}$ isomer)

Method C. In a flask containing 4-bromobenzaldehyde $(6.4 \mathrm{mmol})$ dissolved in $3 \mathrm{~mL}$ of $\mathrm{Ac}_{2} \mathrm{O}$ and kept at $140^{\circ} \mathrm{C}$ a solution of 4-picolin (4 mmol) dissolved in $1 \mathrm{~mL}$ of $\mathrm{Ac}_{2} \mathrm{O}$ is added dropwise during a few minutes; the mixture is kept at $140^{\circ} \mathrm{C}$ during $4 \mathrm{~h}$, then a $2 \mathrm{M}$ aqueous $\mathrm{HCl}$ solution is added and the mixture extracted once with $20 \mathrm{~mL}$ of $\mathrm{CH}_{2} \mathrm{Cl}_{2}$. The aqueous layer is made basic with $2 \mathrm{M}$ aqueous $\mathrm{NaOH}$ solution and the mixture extracted 4 times with overall $50 \mathrm{~mL}$ of $\mathrm{CH}_{2} \mathrm{Cl}_{2}$. After drying, TLC analysis (AcOEt/hexane 2:1) shows mostly 4-bromobenzaldehyde in 
the acidic extract and two spots attributed to Z- and E-4-[2-(4-bromo-phenyl)-vinyl]-pyridine products by comparison with authentic samples. Furthermore, GC-MS of the solution shows two peaks with $\mathrm{m} / \mathrm{z}$ 260. The solution is evacuated and the residue weighed $230 \mathrm{mg}$ (22\% yield). This residue is then dissolved in AcOEt, transferred in a Pyrex vessel and photolyzed at $366 \mathrm{~nm}$ for 1h30'. The reaction is followed by TLC and stopped when the reagents are no longer present. $0.35 \mathrm{mmol}$ of the crude product (9-bromobenzo[h]isoquinoline) is then dissolved in $5 \mathrm{~mL}$ of dimethylacetamide; to this solution $1 \mathrm{mmol}$ of 4-vinylpyridine, $1 \mathrm{mmol}$ of sodium acetate and $1 \%$ of bis(triphenylphosphine)palladium (II) dichloride were added and the mixture stirred at $140^{\circ} \mathrm{C}$ during $48 \mathrm{~h}$. At the end, the mixture is cooled, diluted with $2 \mathrm{M}$ aqueous $\mathrm{NaOH}$ and extracted 4 times with overall $50 \mathrm{~mL}$ of $\mathrm{CH}_{2} \mathrm{Cl}_{2}$. GC-MS analysis reveals traces $(<5 \%)$ of both $\mathbf{6 Z}$ and $\mathbf{6 E}$ and a large amount of the starting material.

Compound characterization. NMR spectra were performed on Bruker Avance 500 spectrometer operating at proton resonance frequency of $500 \mathrm{MHz}$. The products were dissolved in suitable deuterated solvent and tetramethylsilane (TMS) was added as internal reference. GCMS analyses were obtained from an Agilent GC 6890 series gas-chromatograph equipped with a MS 5973N mass spectrometer detector. Electrospray mass spectra (ESI-MS) were acquired on a Bruker Esquire 3000+ by infusion of suitable solution directly in the ESI source at the rate of $4 \mu \mathrm{L} / \mathrm{min}$ The ATR FT-IR spectra were recorded or on a Avatar 370-Thermo or on a Bruker Tensor 27. UV-vis spectra were run on a Thermo Evolution 500 spectrometer with $10^{-5} \mathrm{M}$ solutions in the appropriate solvent. Fluorescence spectra were run on a Jasco 770 spectrofluorimeter utilizing the same solutions used for the UV-vis spectra. HPLC analyses were run on a Perkin-Elmer series 200 instrument using a Zorbax Eclipse XDB-C18 analytical column 4,6 x $150 \mathrm{~mm}, 5-\mu \mathrm{m}$. Solvent $\mathrm{CH}_{3} \mathrm{OH} / \mathrm{H}_{2} \mathrm{O}$ 8/2, flow rate $1.0 \mathrm{~mL} / \mathrm{min}$. Elemental analyses were run at the Dipartimento di Chimica, Materiali e Ingegneria Chimica del Politecnico di Milano.

6Z. Oil, ESI-MS: 283 [M+H] ${ }^{+}$; IR: 2963 ; 2924 ; 1706 ; 1590 ; 1437 ; 1401 ; 1331 ; 1238; 1062; $\mathrm{UV}\left(\mathrm{CH}_{3} \mathrm{OH}\right) \lambda$ (log $\left.\varepsilon\right) 205$ (4.24), 249 (4.24), 321(4.01). ${ }^{1} \mathrm{H}$ NMR (500 MHz, $\mathrm{CD}_{3} \mathrm{OD}, 25^{\circ} \mathrm{C}, \delta$, ppm): 9.57, s, 1H, H1; 8.57, br. s, $1 \mathrm{H}, \mathrm{H} 10 ; 8.44,1 \mathrm{H}, \mathrm{d}, J=5.6 \mathrm{~Hz}, \mathrm{H} 3$; 8.23, m, 2H, H1(py); 7.84, $1 \mathrm{H}, \mathrm{d}, J=8.9 \mathrm{~Hz}$, H5 or H6; 7.71, d, $1 \mathrm{H}, J=8.5 \mathrm{~Hz}, \mathrm{H7} ; 7.70,1 \mathrm{H}$, dd, $J=5.5,1.2 \mathrm{~Hz}$, H4; 7.61, $1 \mathrm{H}, \mathrm{d}, J=8.9 \mathrm{~Hz}$, H6 or H5; 7.36, $1 \mathrm{H}$, dd, $J=8.5,1.8 \mathrm{~Hz}, \mathrm{H8} ; 7.13,2 \mathrm{H}, \mathrm{m}, \mathrm{H} 2(\mathrm{py}) ; 7.01$, $1 \mathrm{H}, \mathrm{d}, J=12.3 \mathrm{~Hz}, \mathrm{H} 11 ; 6.54,1 \mathrm{H}, \mathrm{d}, J=12.3 \mathrm{~Hz}, \mathrm{H} 12$.

Anal. calc. for $\mathrm{C}_{20} \mathrm{H}_{14} \mathrm{~N}_{2}$ : C 85.08, H 5.00, N 9.92; found C 84.76, H 5.01, N 9.90.

6E. Mp 184-186 C; ESI-MS: 283 [M+H] ${ }^{+}$; IR: 3022; 1613; 1589; 1410; 1239; 1213; 969; 848;

$\mathrm{UV}\left(\mathrm{CH}_{3} \mathrm{OH}\right) \lambda$ (log $\varepsilon$ ): 205 (4.11), 239(4.24), 270(4.01), 332 (4.23). Anal. calc. for $\mathrm{C}_{20} \mathrm{H}_{14} \mathrm{~N}_{2}$ : C 85.08, H 5.00, N 9.92; found C 84.59, H 4.99, N 9.95.

2,13-Diaza[5]helicene (5). ${ }^{12}$ The irradiation was carried out in methanol $(0.030 \mathrm{~g}$ in $200 \mathrm{~mL})$ for 50 ' at $365 \mathrm{~nm}$. At the end of irradiation, the solvent was removed under vacuum, and the residue (0.030 g) was chromatographed on silica gel $\left(\mathrm{CH}_{3} \mathrm{CN}\right.$ : 2-propanol : ethanol 6:3:1) recovering 6 (0.020 g) and obtaining 5 (0.008 g, yield 27\%, yield on converted base $80 \%)$ as a light yellow 
solid, mp 255-260 ${ }^{\circ}$. Mass (m/e) 279, 253; ESI-MS: 281 [M+H] ${ }^{+}$; IR: 2960; 2921; 2852; 1613; $1542 ; 1401 ; 1260 ; 1228 ; 1029 ; 858 ; 801$, UV $\left(\mathrm{CH}_{3} \mathrm{OH}\right) \lambda(\log \varepsilon): 203(4.49), 225(4.60)$, 266(4.24), 307 (4.26). ${ }^{1} \mathrm{H}$ NMR (500 MHz, $\mathrm{CDCl}_{3}, 2^{\circ} \mathrm{C}, \delta$, ppm): 9.92, s, $1 \mathrm{H}, \mathrm{H} 1 ; 8.60$, d, $1 \mathrm{H}$, $J=5.4 \mathrm{~Hz}, \mathrm{H3}$; 8.08, 1H, d, $J=8.7 \mathrm{~Hz}$, H5 or H6; 7.97, s, $1 \mathrm{H}, \mathrm{H7} ; 7.91,1 \mathrm{H}, \mathrm{d}, J=8.7 \mathrm{~Hz}$, H6 or $\mathrm{H} 5$; 7.76, d, $1 \mathrm{H}, J=5.4 \mathrm{~Hz}, \mathrm{H} 4$. Anal. calc. for $\mathrm{C}_{20} \mathrm{H}_{12} \mathrm{~N}_{2}$ : C 85.69, $\mathrm{H} \mathrm{4.32,} \mathrm{N} \mathrm{9.99;} \mathrm{found} \mathrm{C}$ 85.84, H 4.30, N 9.97.

2,9-Diaza-dibenzo[a.h]anthracene (7). The irradiation was carried out in hexane $(0.030 \mathrm{~g}$ in $200 \mathrm{~mL}$ ) for 1h30' at $360 \mathrm{~nm}$. At the end of the irradiation, the solvent was removed under vacuum, and the residue $(0.029 \mathrm{~g})$ was chromatographed on silica gel $\left(\mathrm{CH}_{3} \mathrm{CN}\right.$ : 2-propanol : ethanol 6:3:1) recovering $6(0.002 \mathrm{~g})$ and obtaining 5 as a light yellow solid $(0.021 \mathrm{~g}$ in $70 \%$ yield); and 7 as a brown-red solid (0.004 g 15\% yield).

7: mp 242-250 ${ }^{\circ} \mathrm{C}$, mass (m/e) 280, 253; ESI-MS: $281[\mathrm{M}+\mathrm{H}]^{+}$; IR: 2945; 2836; 1648; 1541; 1507; 1456; 1418; 1015; UV $\left(\mathrm{CH}_{3} \mathrm{OH}\right) \lambda(\log \varepsilon) 216(4.58), 266(4.27), 308(4.10), 335(4.11) ;{ }^{1} \mathrm{H}$ NMR (500 MHz, $\left.\mathrm{CDCl}_{3}, 25^{\circ} \mathrm{C}, \delta, \mathrm{ppm}\right): 9.04, \mathrm{~s}, 1 \mathrm{H}, \mathrm{H} 1 ; 8.48$, d, $1 \mathrm{H} \mathrm{J}=5.7 \mathrm{~Hz}, \mathrm{H3} ; 7.85,1 \mathrm{H}$, d, $J=8.50 \mathrm{~Hz}, \mathrm{H} 5$ or H6; 7.77, s, 1H, H7; 7.76 1H, d, $J=8.50 \mathrm{~Hz}$, H6 or H5; 7.70, d, $1 \mathrm{H} J=5.7$ $\mathrm{Hz}$, H4. Anal. calc. for $\mathrm{C}_{20} \mathrm{H}_{12} \mathrm{~N}_{2}$ : C 85.69, H 4.32, N 9.99; found C 85.75, H 4.30, N 9.96.

7,8-Diazabenzo[ghi]perylene (9). The irradiation was carried out in hexane (0.030 g in $200 \mathrm{~mL})$ for 3h30' at $365 \mathrm{~nm}$. At the end of irradiation, the solvent was removed under vacuum, and the residue $(0.029 \mathrm{~g})$ was chromatographed on silica gel $\left(\mathrm{CH}_{3} \mathrm{CN}\right.$ : 2-propanol : ethanol 6:3:1) obtaining 7 in (0.004 g, 13\% yield ) and 9 as a dark orange solid ( 0.023 g, 77\% yield)

9: mp 226-234 ${ }^{\circ} \mathrm{C}$, mass (m/e) 278; ESI-MS: 279 [M+H] ${ }^{+}$; IR: 2966 ; 2922 ; 1613 ; 1594; 1559; 1429 ; 1400 ; 1368 ; 1331 ; 1089; 856; UV ( $\left.\mathrm{CH}_{3} \mathrm{OH}\right)$ (log ع) 203(4.61), 252 (4.46), 287(4.36), 299(4.23), 353(3.62), 373(3.74), 393(73.86) ${ }^{1} \mathrm{H}$ NMR (500 MHz, $\left.\mathrm{CD}_{3} \mathrm{COCD}_{3}, 2^{\circ} \mathrm{C}, \delta, \mathrm{ppm}\right)$ : 9.40, d, 1H, $J=5.2 \mathrm{~Hz}$, H6; 8.66, s, 1H, H2; 8.56, 1H, d, $J=8.8 \mathrm{~Hz}, \mathrm{H3}$ or H4; 8.34, d, 1H, $J=$ $5.2 \mathrm{~Hz}, \mathrm{H} 5$; 8.33, $1 \mathrm{H}, \mathrm{d}, J=8.8 \mathrm{~Hz}, \mathrm{H} 4$ or H3. Anal. calc. for $\mathrm{C}_{20} \mathrm{H}_{10} \mathrm{~N}_{2}$ : C 86.31, H 3.62, N 10.07; found C 86.00, H 3.63, N 10.02.

Photolysis in different solvents. $10 \mathrm{~mL}$ of $2.010^{-4} \mathrm{M}$ solution of $\mathbf{6}$ in the appropriate solvent was irradiated for $1 \mathrm{~h}$ at $363 \mathrm{~nm}$. At the end of irradiation, the solvent was removed under vacuum, and the residue was dissolved in $10 \mathrm{~mL}$ of $\mathrm{CH}_{3} \mathrm{OH}$ and analysed via HPLC as described above. Peak areas were corrected for the different absorbances.

\section{References and Notes}

1. Abbate, S.; Caronna, T.; Longo, A.; Ruggirello, A.; Turco Liveri, V. J. Phys. Chem. B 2007, 111,4089

2. Abbate, S.; Bazzini, C.; Caronna, T.; Fontana, F.; Gambarotti, C.; Gangemi, F.; Longhi, G.; Mele, A.; Natali Sora, I.; Panzeri, W. Tetrahedron 2006, 62, 139 
3. Bazzini, C.; Brovelli, S.; Caronna, T.; Gambarotti, C.; Giannone, M.; Macchi, P.; Meinardi, F.; Mele, A.; Panzeri, W.m Recupero, F.; Sironi, A.; Tubino, R. Eur. J. Org. Chem. 2005, 1247.

4. Caronna, T.; Gabbiadini, S.; Mele, A.; Recupero, F. Helv. Chim. Acta 2002, 85, 1.

5. (a) Muszkat, K.A.; Sharafi-Ozeri, S. Chem. Phys. Lett. 1976, 42, 99. (b) Laarhoven, W. H. Rec.Trav.Chim. Pays-Bas 1983, 102, 185.

6. 6. Gaussian 03, Revision B.05, Frisch, M.J.; Trucks, G.W.; Schlegel, H.B.; Scuseria, G.E.; Robb, M.A.; Cheeseman, J.R.; Montgomery, J.A. Jr.; Vreven, T.; Kudin, K.N.; Burant, J.C.; Millam, J.M.; Iyengar, S.S.; Tomasi, J.; Barone, V.; Mennucci, B.; Cossi, M.; Scalmani, G.; Rega, N.; Petersson, G.A.; Nakatsuji, H.; Hada, M.; Ehara, M.; Toyota, K.; Fukuda, R.; Hasegawa, J.; Ishida, M.; Nakajima, T.; Honda, Y.; Kitao, O.; Nakai, H.; Klene, M.; Li, X.; Knox, J.E.; Hratchian, H.P.; Cross, J.B.; Adamo, C.; Jaramillo, J.; Gomperts, R.; Stratmann, R.E.; Yazyev, O.; Austin, A.J.; Cammi, R.; Pomelli, C.; Ochterski, J.W.; Ayala, P.Y.; Morokuma, K.; Voth, G.A.; Salvador, P.; Dannenberg, J.J.; Zakrzewski, V.G.; Dapprich, S.; Daniels, A.D.; Strain, M.C.; Farkas, O.; Malick, D.K.; Rabuck, A.D.; Raghavachari, K.; Foresman, J.B.; Ortiz, J.V.; Cui, Q.; Baboul, A.G.; Clifford, S.; Cioslowski, J.; Stefanov, B.B.; Liu, G.; Liashenko, A.; Piskorz, P.; Komaromi, I.; Martin, R.L.; Fox, D.J.; Keith, T.; Al-Laham, M.A.; Peng, C.Y.; Nanayakkara, A.; Challacombe, M.; Gill, P.M.W.; Johnson, B.; Chen, W.; Wong, M.W.; Gonzalez, C.; Pople, J.A.; Gaussian, Inc., Pittsburgh PA, 2003

7. Glendening, E. D.; Weinhold, F.; J. Comp. Chem. 1998, 19, 610

8. (a) Wiberg, K. B. Tetrahedron 1968, 24, 1083. (b) Glendening, E. D.; Weinhold, F. J. Comp. Chem. 1998, 19, 620

9. (a) Masetti, F.; Mazzucato, U.; Birks, J. R. Chem. Phys. 1975, 301. (b) Gonzalo Rodriguez, J.; Martìn-Villamin, R.; Lafuente, A. Tetrahedron 2003, 59, 1021

10. (a) Frank, W.C.; Kim Y.C.; Heck R.F. J. Org. Chem. 1978, 43, 2947. (b) Li, M.; Hua, R. Appl. Organomet. Chem. 2008, 22, 297. (c) Chandrasekhar, S.; Narsihmulu, Ch.; Shameem Sultana, S.; Ramakrishna Reddy, N. Org. Lett. 2002, 4, 4399. (d) Aloui, F.; El Abed, R.;. Ben Assine B. Tetrahedron Lett. 2008, 49, 1455

11. Bernardi, R.; Caronna, T.; dal Pio Luogo, D.; Morrocchi, S.; Poggi, G.; Vittimberga, B. M. J. Chem. Soc., Perkin 1 1996, 1593

12. Compound 5 was already reported in ref 4. Despite the fact that the NMR spectra show the same number of signals and the same multiplicity and they appear quite clean, the chemical shifts are different. Moreover there is a strong difference in the melting points. Due to the small amount of material obtained at that time, it was not possible to make a comparison between the former product and the one obtained now. We have no explanation for this difference. 